\title{
CONFUTOS AGRÁRIOS E MEMÓRIA DE MULHERES CAMPONESAS
}

\author{
MARISTELA DE PAULA ANDRADE \\ Universidade Federal do Ma ranhão
}

\begin{abstract}
Resumo: Este artigo toma para objeto de reflexão questões suscita daspor pesquisa com mulheres c a mponesas, a utodenominadas e conhecidas como quebradeiras de coco babaçu, acerca de conflitos em que estiveram e se encontram envolvidas, elas e suas famílias, no Maranhão. Procura-se refletir sobre aspectos metodológicos suscitados pela a nálise de depoimentos de lideranças camponesas femininas que reconstroem, hoje, um tempo vivido no passado.

Palavras-chave: conflito a grário; relações de gênero; memória camponesa.
\end{abstract}

\section{Ap resentação}

Nossa intenção é extrair algumas lições de método revisitando uma pesquisa realizada em $2003,{ }^{1}$ com mulheres e homens, mas principalmente junto às chamadas quebradeiras de coco babaçu, integrantes de famílias que estiveram envolvidas na luta pela terra e pela cobertura vegetal, na região do Mearim, no Maranhão, nos anos $80 .^{2}$ Essa s mulheres se destacam, hoje, como lideranças expressivas, em diferentes níveis da organização política e econômica das quebradeiras de coco no Maranhão, Pará, Tocantins e Piauí.

O objetivo é refletir sobre representações femininas acerca da participação de homense mulheres naquelas lutas, tendo em conta que o fazem dos luga res instituciona is ocupados, atualmente, junto ao Movimento Interestadual das Quebradeiras de Coco (MIQCB); à Associação em Áreas de Assentamento do Estado do Maranhão (ASSEMA); à Câma ra dos Verea dores (algumas são verea doras); à sfa mília s dos povoa dos onde residem,

Copyright $(2006$ by Revista Estudos Feministas.

${ }_{1}^{1}$ Pesquisa realizada juntamente com Luciene Dias Figueiredo, então mestranda do NEAF/UFPA, tendo como assistente o estudante de geografia da UFMA J osoaldo Lima Rêgo, bolsista de iniciação científica do CNPq (PIBIC), no âmbito do Projeto Olhar Crítico (Dfid-Action Aid Brasil). A pesquisa envolveu trabalho de campo, com permanência das pesquisadoras nos povoados, observação direta, participação em reuniões da Asso ciação em Áreas de Assentamento do Esta do do Maranhão (Assema) e do Movimento Interestadual das Quebradeiras de Coco (Miqcb), e entrevistas gravadas com mulheres, homens, jovens e casa is.

2 Maristela de PAULA ANDRADE e Luciene FIG UEIREDO, 2004. As pessoas entrevista das tinham conhecimento dos fins a que se destinavam as entrevistas e permitira $m$ que seus depoimentos fossem utiliza dos em futuras public ações, conforme reuniões rea liza das em cada local pesquisa do pa ra explic a r os objetivos do estudo. 
na condição de lideranças locais; à Escola Família Agrícola, instituição de ensino funda mental que fund a ram para seusfilhos; às fábricas de sabonetes, de papel recic la do e de doces, mantidas por elas e sua s fa mília s em distintos povoados; à s coopera tiva s e às chamadas cantinas organizadas após a conquista da terra, de modo a se livrarem dos atravessadores. Enfim, pretendemos perceber como reconstroem o passado, tendo em vista que o fazem a partir dos vários lugares que ocupam hoje, em sua bem-sucedida organiza ção econômica e política, na qual emergira m como sujeito coletivo, assumindo papel preponderante.

Proc uramosnos centrarnas especificida des da fa mília camponesa e na plastic ida de das estratégias econômicas, mormente daquelas que essa unidade de produção e consumo pode adotar em contextos de conflitos a grários.

Uma questão de fundo a travessa essa reflexão - certamente ainda sem resposta, e que somente a continuida de de pesquisas etnográ fic as permitirá perseguir - rela tiva a o fato de que, muitas vezes, extraem-se representações de depoimentos como se não fossem a tra vessadas pela posição ocupada pelos informantes hoje, como se a memória coletiva pudesse fluir de modo espontâneo e puro das consciências ind ividuais, como se não fosse, conforme nos lembra Portelli, ${ }^{3}$ media da porideologias, lingua gens, senso comum e instituições.

\section{0 tempo do coco preso}

Toda vez que solic itamos a essas mulheres - e em geral o fazemos à socupantes de posições de destaque, hoje, no movimento das quebradeiras - para discorrerem sobre as lutas que as levaram à conquista da terra e dos babaçuais, elas remontam ao tempo em que o acesso a os babaçuais e, portanto, a extração do babaçu deixou de ser livre. Toda vez que lhes pedimos para comentar sobre o processo que as levou a se livrardos a tra vessadores, a controlar o beneficiamento das amêndoas, a comercialização e, a té mesmo, a exportação do óleo para o merca do internacional, a s na rrativas remontam a o denominado tempo do coco preso. A memória das lutas travadas para garantir o livre acesso a esse recurso vegetal remete, nas na rrativas, a um tempo em que os babaçuais deixaram de ser recursos a bertos, usufruídos em sistema de uso comum.

o chamado tempo do coco preso não corresponde, nec essariamente, a o tempo cronológico. Nós o datamos na década de 80 , por ter sido esse o período em que as fontes escritas registraram o maior número de confrontos, de mortes, de incêndio de povoados, de destruição de casas, de escolas, de igrejas, de prisões, de ataques de pistoleiros. Quando as informantes se referem ao tempo do coco preso, porém, podem estar a ludindo aos anos 70, a os 60, aos 50, ou seja, ao processo de fechamento dos babaçuais, que cada uma foi experimentando e do qual se lembra e rememora como um processo vivido.

Esse tempo é demarcado, portanto, poracontecimentos de profunda signific ação para a vida dessas famílias ta mbém no presente, como diz Maurice Ha lb wa chs ${ }^{4}$ - porque a té hoje essas famílias lutam pelo acesso livre à cobertura vegetal, pela entrada livre nos babaçuais, estejam eles ou não dentro de propriedades privadas. Manter os babaçuais livres ao acesso das famílias, disponíveis a o usufruto comum, é o lema de sua luta, originando a logomarca do sabonete que produzem - Babaçu Livre - e também o nome pelo qual são conhecidas as leis munic ipa is que conseguiram - as leis do babaçu livre. 0

\footnotetext{
${ }^{3}$ Alessand ro PORTEШ, 1996.

${ }^{4}$ HALBWACHS, 2004, p. 126.
} 
tempo do coco preso marca a história do grupo, modelando, poroposição, sua identidade atual.

Em outros contextos, os camponeses de outras regiões aludem ao tempo da sujeição, ao tempo do cativeiro, para significar que estiveram sujeitos ao controle do proprietário das terras, pagando renda para cultivar. Desejavam a terra liberta. No caso das quebradeiras, procuravam libertar o coco. Era o recurso vegetal que estava preso, cativo, cercado pelo arame farpado, incendiado, demubado, morto, extinto. Esta, a inda hoje, é a luta dessas mulheres - preservar os ba baçua is, lutar pelo a proveita mento integ ral do coco, evitar que se transforme em carvão para a limentar siderurgias. ${ }^{5}$

0 tempo do coco preso, repetidas vezes enunciado nas narrativas, aponta, por inversã 0 , para um traço diacrítico da identidade desses grupos. Esses grupos lutaram contra o fechamento dos babaçuais, pela libertação de um recurso vegetal que, em seus sistemas de representação da natureza, era pensado e vivido como um recurso aberto, a ser apropriado pelo trabalho familiar e não para ser açambarcado individualmente pelos fazendeiros.

O tempo do coco preso é, portanto, de dor, de sofrimento, de fome, de perda de identidade. Isso porque não havia mais terras para cultivar. A expropriação já se completara. As terras já se havia $\mathrm{m}$ transformado em pastagens, via incentivos ofic ia is, e 0 extrativismo do babaçu se a presentava como únic a altemativa de sobrevivência àsfa mílias camponesas. Dentre as atividades econômicas dantes praticadas - cultivo do solo, extra tivismo, ca ça, artesa na to, pesca - as fa mílias viam-se, subita mente, restrita sà coleta e quebra do coco e venda das a mêndoas a os fazendeiros. De a tividade preponderantemente feminina, passara a constituir-se na únic a a garantira a limentação do grupo fa miliar e a ser praticada porhomens, mulheres, crianças, jovens e idosos. Completand o o cerco à economia camponesa, os fazendeiros haviam passado a cercar os cocais, a prender o coco como dizem as informantes. Tra tava-se, portanto, de lutar para libertá-lo, de modo a se liberta rem a si mesmas e as suas famílias.

É sobre todo esse processo, que se estende aos dias de hoje, que nos falam os entrevistados, sobretudo as mulheres. Nesse momento, por volta dos 80 , foram lançadas a uma posição de primeiro plano nos enfrentamentos com vaqueiros, pistoleiros e fazendeiros. Foram principalmente elas que, no tempo do coco preso, no exercício da atividade de extração, necessitaram adentrar as cercas de arame farpado, a companhadas de suas crianças, a pesar das proibições dos fazendeiros, das a meaças dos vaqueiros, das a gressões físic as e das humilhações. Ou o faziam ou a família não se a limentava.

\section{O protagonismo das mulheres na luta pelo acesso aos babaçuais}

Os relatos sobre esse tempo são bastante chocantes, dolorosos, o que nos faz lembrar Portelli, mais uma vez, ao descrever a dor e o luto dos sob reviventes de Civitella: "as na rrativas de Civitella nos deixam estarrecidos. No entanto, a ta refa do especialista, após recebido o impacto, é se afastar, respirar fundo, e voltar a pensar [...] interpretar critica mente todos os doc umentos e narrativas [...]". ${ }^{6}$

\footnotetext{
${ }^{5}$ Uma questão a tual que se acrescenta à sa meaçasà integridade dos babaçuaise à expansão dasatividades das quebradeiras de coco são as discussões e propostas em tomo do biodiesel, aspecto que não desenvolveremos neste artigo.

${ }^{6}$ PORTEU, 1996, p. 106.
} 
Nesse sentido, para a lém dos rela tos, devemos qua lific ar os enuncia dos, situa ndo quem fala e de onde fala, atentando para o fato de que essas mulheres são lideranças que modelam o passado de um lugar muito especial no presente, da posição de proeminência hoje ocupada, lugar este reconhecido pelos homens, pois, como diz seu Zé Mundico, gerente da Cooperativa de Pequenos Produtores Agro Extrativistas de Lago do J unco (Coopalj), "a mulher hoje é a estrela da cooperativa". ${ }^{7}$

Interp retar critic a mente as na rra tivas não quer dizer desqua lific ar os depoimentos das entrevistadas, mesmo porque não estamos buscando a verdade, mas lidando com representações, com verdades, no plural. Encontramo-nos diante de várias verdades, ditas sob muitas vozes. A memória coletiva é polifônic a, cada qual a firmando, na sua voz, a partir da sua posição, a história do grupo. Sendo assim, erramos quando, a partir de uma leitura ingênua das narrativas, tentamos desc rever a história dos conflitos e das lutas, linea rmente, por etapas, como muitas vezes o fazemos: inic ia Imente as mulheres lutaram pelo coco; num segundo momento os homens decidiram apoiá-las e, a partir daí, desencadeou-se a luta pela terra, a luta pela reforma agrária propriamente dita.

Evidentemente, há um protagonismo das mulheres nesse chamado tempo do coco preso. Quando narram que passavam por baixo das cercas de arame farpado, enfrentando a humilhação no confronto com os va queiros - que lhes tomavam os cestos com os cocos coletados, quebravam seus instrumentos de trabalho, lhes batiam com chicote $^{8}$-, é como se os homens não existissem, como se elas e seus filhos existissem sozinhos no mundo. Sabemos, no entanto, que a família camponesa é, a o mesmo tempo, uma unidade de produção e uma unida de de consumo. Todos os seus membros produzem em conjunto, obed ec end o a uma divisão sexual e etá ria do trabalho, e todos consomem o que foi produzido. Daí a dific uldade dos economistas em calcular, com base nas categorias da economia capitalista, a renda da família camponesa, já que o que é produzido serve, a o mesmo tempo, para o auto-consumo e para comercializar e, assim, adquirir o que não produzem. Sabemos que o fruto do trabalho é compartilhado por todos, conforme suas necessidades.

Inadvertidamente, no entanto, muitas vezes, trabalhamos com as categorias de a ná lise da família urbana, cujos membros vivem de forma a tomizada, embora vivam sob o mesmo teto. Tomamos litera Imente as na rrativas e entendemos que, de fato, as mulheres lideraram as lutas e os homens só se engajaram nelas a posteriori. É assim que vários comentaristas e media dores têm se referido à construção desse movimento, a penas como de mulheres e não como movimento de famílias.

De fato, como pesquisadoras mulheres, embora pertencentes à outra classe, à outra cultura, pod emos nos sentir bastante toc a das pelos depoimentos dessas entrevista das, pela dore sofrimento que representa $m$, e resva lar para um ponto de vista militante ingênuo. Para evitá-lo, podería mos nos pergunta ronde estavam os homens no momento dos conflitos ou como se dão as relações entre homens e mulheres nessa sociedade - como são pensados o ser mulher e o ser homem nessas culturas, o que entendem por trabalho feminino e masculino, por trabalho leve e trabalho pesado. Poderíamos nos questionar sobre como se davam as relações entre homens e mulheres naquele momento, como se desenhavam as estratégias de sobrevivência dos grupos familiares, de modo que cada membro se dividia na tarefa de conseguir a limentos, já que o acesso à terra estava cada vez mais interditado.

\footnotetext{
${ }^{7}$ Exc erto de depoimento extraído de PAULA ANDRADE e FIGUEIREDO, 2004.

${ }^{8}$ Vide depoimentos a esse respeito em PAULA ANDRADE e FIGUEIREDO, 2004.
} 
Em vez de tomar literal e ingenuamente o que está sendo dito, além de situar quem fala, devemos contextua lizar esse discurso no âmbito da cultura e da economia desses grupos.

J ulie Cruiksha nk, ${ }^{9}$ a o a na lisa r exemplos de estud os rea liza dos nas Filip inas, na Nova Zelândia, em Uganda e na Colúmbia Britânica, nos diz que uma das contribuições ma is diretas que a tradição oral pode prestar ao discurso acadêmico é complicar nossas perguntas. Historiadores e antropólogos, diz ela, em sua tarefa de examinar o passado, indagam o que realmente aconteceu, mas em geral fazem isso utilizando categorias e conceitos ocidenta is.

Pergunta mosse não corremos o risco de procederassim qua nd o ima gina mos essas mulheres como agentes socia is à parte, avulsas, e não como integrantes de unidades familiares, fa zendo parte de estra tégias de sobrevivência e de luta que incluíam homens, mulheres, jovens, idosos e crianças; quando pensamos a família camponesa nos termos da família urbana; quando entendemosa dominação masculina de modo trans-histórico e trans-cultural.

Evidentemente, quem fala o faz do lugar de vencedora. Hoje é uma liderança, olha para o passado após a conquista da terra, depois de terem se organizado economicamente, terem fundado uma escola para seus filhos, terem montado cooperativas. O passado é reconstituído desse ponto de vista. É desse lugar que o reconstroem, que interpretam seu papel na luta, falando de sua participação e daquela dos seus maridos, assim como dos outros homens na conquista dos babaçuais e da terra. Algumas dessas lideranças subsumem ou omitem completamente a participação dos homens. Falam no feminino. É assim também que as entidades de mediação elaboram seu disc urso e, igua Imente, os a poia dores intema ciona is, reforç a ndo um disc urso a ncora do no que chamam de relações de gênero (ao menos nas relações de gênero tal como conceitua das do ponto de vista da mulherbranca, ocidental, e impostas à s mulheres do chamado Terceiro Mundo via instituições financeiras e ONGs internaciona is). ${ }^{10}$

O discurso dessas mulheres passa, portanto, a sofrer a interferência de ideologias, da ação de instituições. Algumas autoras não ocidentais, como Chandra Mohanty, ${ }^{11}$ cha mam a a tenção para certo colonia lismo disc ursivo de parte da sfeminista socidenta is, que a cabam produzindo uma leitura etnocêntric a e reducionista das condições de vida das mulheres do chamado Terceiro Mundo. ${ }^{12}$ Criticam a a plic ação da categoria mulher, como categoria essencialista, predefinida de fora, sem levarem conta as relações socia is em que essa mulher do chamado Terceiro Mundo está inserida.

A memória dessas quebradeiras de coco também é dividida, para nos a propriar, ainda, de uma expressão de Portelli, ${ }^{13}$ embora utilizando-a em outro sentido. Mesmo valorizando seu papel como protagonistas da luta, a inda que ressaltando sua posição de lideranças, elas nos explicam, em suas narrativas, por que os homens não estavam presentes em muitos momentos, as razões de esta rem escondidos e por que estava m elas enfrentando a polícia e os jagunços quando estes chegavam a os povoados. 0 enfrentamento entre seus homens e os antagonistas, na quele momento, seria mais grave, ma is violento, principalmente porque os homens em idade adulta, do povoado, estavam

\footnotetext{
${ }^{9}$ CRUIKSHANK, 1996, p. 163.

${ }^{10}$ Vandana SHIVA, 1995, p. 90-97.

${ }_{11}$ Apud Andreu VIOLA, 2000, p. 38.

${ }^{12}$ Cf. Arturo ESCOBAR, 1996.

${ }^{13}$ PORTEШ, 1996, p. 129.
} 
sendo ca ça dos pelos pistoleiros. Reg istra va-se, porta nto, uma divisã o do traba lho de guerra, estrategicamente pensada. ${ }^{14}$

Em outros momentos, as mulheres partiam para o confronto com os que estavam derrubando as palmeiras, enquanto os homens ficavam por perto, vigilantes, e apareceriam caso elas sofressem ameaças mais graves. Havia, desse modo, o que denominamos de uma divisão sexual e etária do trabalho de guerra. As crianças, que transitam melhor pelos caminhos, pelo chamado mato, sem chamar muito a atenção, leva va m comida, entregavam recados. Mulheres, criançase idosos cuidava $m$ de guardar os povoados, encarregando-se também de empatar as demubadas de palmeiras. Em outras situações, era necessá ria a presença dos homens em idade adulta para enfrentar os que pretendiam destruir os babaçuais.

\section{Considerações fina is}

Gostaríamos de concluir com algumas indagações que, embora se refiram ao caso específic 0 , talvez possa m serúteis a os que trabalham com dados de memória social, com representações do passa do, com reconstituições de histórias de lutas, com memória camponesa.

Como reconstituir as histórias das lutas incorporando os vários pontos de vista, as diferentes verdades, ditas de vários lugares, por mulheres, homens, crianças e idosos?

Como escapar à tentação da estatística ingênua, procurando o ponto de vista médio, ou os pontos de vista recorrentes?

Como escapardasarmadilhas colocadas pelo ponto de vista da mulher ocidental que nos conduz a perceber a mulher camponesa, necessa riamente, como vítima, subjugada, dominada, nos termos do que se passa em nossa sociedade?

\section{Referências bibliográficas}

CRUIKSHANK, J ulie. "Tra dição oral e história oral: revendo a lgumas questões". In: FERREIRA, Marieta de M.; AMADO, Janaína (Orgs.). Usos e abusos da história oral. Rio de Janeiro: FGV Ed., 1996. p. 149-164.

ESCOBAR, Arturo. La invención del Tercer Mundo: construcción y desconstrucción del desarollo. Barcelona: Grupo Editorial Norma, 1996.

HALBWACHS, Maurice. A memória coletiva. São Paulo: Centa uro Editora, 2004.

PAULA ANDRADE, Maristela de; FIGUEIREDO, Luciene Dias. "Na lei e na marra: a luta pelo livre a cesso a os babaçuais". In: AC TION AID BRASIL. Olhar crític o sobre partic ipação e cidadania na construção de políticas públicas. Rio de J a neiro: Action Aid Bra sil, 2004. p. 1-41. CD-ROM.

PORTEШ, Alessandro. "O massacre de Civitella Val di Chiana: mito, política, luto e senso comum". In: FERREIRA, Ma rieta de M.; AMADO, J a naína (Orgs.). Usos e a busos da história oral. Rio de J a neiro: FGV Ed.,1996. p. 103-130.

SHIVA, Vandana. Abrazar la vida: mujer, ecología y supervivencia. Madrid: Horas y Horas, 1995.

VIOLA, Andreu. Antropología del desarrollo: teorías y estudios etnográficos en América Latina. Barcelona: Paidós, 2000.

\footnotetext{
${ }^{14}$ Dado o ta manho exigido para este artigo, não pudemos inserir depoimentos, que podem ser consultados em nosso outro trabalho, já citado.
} 


\section{Agrarian Conflict and Peasant Memory}

Abstract: This artic le reflects upon questions brought about during research with rural women, who call themselves and are known by others as quebradeiras de coco babaçu (cacao bean breakers). It deals with previous and present c onflic ts in which they and their families have been involved in Maranhão. Methodological concerns about interviews done with peasant and rural women lea ders are disc ussed, emphasizing how pastexperience is reconstructed at the present time.

Key words - Agrarian conflict; Gender Relations; Pea sant Memory. 